\title{
Perspectives of tumor-infiltrating lymphocyte treatment in solid tumors
}

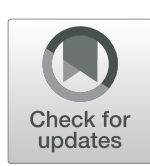

Shuhang Wang ${ }^{1 \dagger}$, Jingwei Sun ${ }^{2 \dagger}$, Kun Chen ${ }^{3 \dagger}$, Peiwen Ma', Qi Lei ${ }^{1}$, Shujun Xing ${ }^{1}$, Zhongzheng Cao ${ }^{2}$, Shujun Sun ${ }^{4}$, Zicheng $\mathrm{Yu}^{5}$, Yarong Liü ${ }^{2^{*}}$ and Ning $\mathrm{Li}^{1^{*}}$

\begin{abstract}
Tumor-infiltrating lymphocyte (TIL) therapy is a type of adoptive cellular therapy by harvesting infiltrated lymphocytes from tumors, culturing and amplifying them in vitro and then infusing back to treat patients. Its diverse TCR clonality, superior tumor-homing ability, and low off-target toxicity endow TIL therapy unique advantages in treating solid tumors compared with other adoptive cellular therapies. Nevertheless, the successful application of TIL therapy currently is still limited to several types of tumors. Herein in this review, we summarize the fundamental work in the field of TIL therapy and the current landscape and advances of TIL clinical trials worldwide. Moreover, the limitations of the current TIL regimen have been discussed and the opportunities and challenges in the development of nextgeneration TIL are highlighted. Finally, the future directions of TIL therapy towards a broader clinical application have been proposed.
\end{abstract}

Keywords: Tumor infiltration lymphocyte, Cancer treatment, Immunotherapy, Gene editing, Clinical trials

\section{Background}

\section{A historical perspective of TIL therapy}

TIL therapy is a type of adoptive cellular therapy leveraging the patient's own immune system to treat tumors. In TIL therapy, TIL is isolated from the tumor site by biopsy or surgery, stimulated and expanded to a large number in vitro with interleukin-2 (IL-2), and then infused back into the patient [1]. In 1982, the pioneer in this field, Dr. Steven Rosenberg, and colleagues at the National Institutes of Health (NIH) isolated TIL from multiple mouse tumor models for the first time [2], and later demonstrated that the combination of cyclophosphamide conditioning, TIL and simultaneous IL-2 administration cured $100 \%$ of mice with hepatic metastases and 50\% with

\footnotetext{
* Correspondence: Lining@cicams.ac.cn; yarong.liu@grit-bio.com

†Shuhang Wang, Jingwei Sun and Kun Chen contributed equally to this work.

${ }^{2}$ Grit Biotechnology Ltd., Shanghai, China

${ }^{1}$ Clinical Cancer Center, National Cancer Center/National Clinical Research Center for Cancer/Cancer Hospital, Chinese Academy of Medical Sciences and Peking Union Medical College, Beijing, China

Full list of author information is available at the end of the article
}

pulmonary metastases in a MC38 colon adenocarcinoma model [3], laying the foundation for the application of TIL in the treatment of advanced cancers in human. The earliest attempt of TIL therapy in the clinic can be traced back to 1988 and achieved a $60 \%$ objective response rate (ORR) in metastatic melanoma [1].

The process of generating TIL usually starts from a pre-rapid expansion phase (pre-REP), where TIL is dissociated from or emigrates out of the tumor fragments and goes through preliminary amplification. Then TIL is further expanded in a rapid expansion phase (REP) in response to stimulators, such as IL-2 and/or feeder cells. The traditional procedure of TIL production is assayed for specific tumor recognition and usually takes 6-8 weeks. However, TIL is prone to exhaustion after longtime culturing in vitro and could not persist for long in patients $[4,5]$. Besides, the low successful rate of growing autologous tumors in vitro led to a more than $50 \%$ dropout rate of patients referred for TIL therapy [6], largely limiting its clinical application [7]. To this end, Dr. Rosenberg and others developed a "Young TIL"

(C) The Author(s). 2021 Open Access This article is licensed under a Creative Commons Attribution 4.0 International License, which permits use, sharing, adaptation, distribution and reproduction in any medium or format, as long as you give appropriate credit to the original author(s) and the source, provide a link to the Creative Commons licence, and indicate if changes were made. The images or other third party material in this article are included in the article's Creative Commons licence, unless indicated otherwise in a credit line to the material. If material is not included in the article's Creative Commons licence and your intended use is not permitted by statutory regulation or exceeds the permitted use, you will need to obtain permission directly from the copyright holder. To view a copy of this licence, visit http://creativecommons.org/licenses/by/4.0/ The Creative Commons Public Domain Dedication waiver (http://creativecommons.org/publicdomain/zero/1.0/) applies to the data made available in this article, unless otherwise stated in a credit line to the data. 
approach that rapidly expands TIL for administration without in vitro selection for tumor reactivity [8], which markedly improves the timeliness of TIL production as well as its survival and efficacy in vivo (Fig. 1). Later on, "Young TIL" has shown comparable clinical outcome with traditional TIL in melanoma patients $[9,10]$. Besides, the effects of different $\mathrm{T}$ cell functional modulators and cytokines on TIL manufacture have also been examined. It has been shown that anti-PD-1, anti-41BB, or anti-CTLA-4 can increase TIL expansion $[11,12]$. Combination of IL-2/15/21 can enhance TIL expansion in lung and colorectal cancer and promote CD8+ T cell percentage as well as TCR clone diversity compared to IL-2 alone [13].

Currently, the most widely-used TIL production method is to isolate infiltrating lymphocytes from tumor tissues and then culture and expand these cells in vitro. Previous studies showed that tumor-specific $\mathrm{T}$ cells can only be found in the peripheral blood at a minimal level post treatment with PD-1 antibodies, but barely detected before the treatment $[14,15]$. Although some researchers isolated $\mathrm{PD}-1^{+} \mathrm{T}$ cells from the peripheral blood mononuclear cells (PBMCs) and tried to define them as tumor-specific $\mathrm{T}$ cells, later studies demonstrated that the percentage of $\mathrm{PD}-1^{+} \mathrm{T}$ cells in the
PBMCs is actually similar between cancer patients and healthy donors, but highly elevated in the lymphocytes infiltrated in tumors [16]. Besides, the PBMCs from both healthy donors and patients contain large numbers of virus-specific $T$ cells [17], further potentiating the rationality of collecting tumor-specific $\mathrm{T}$ cells from tumors as the raw material for TIL production.

\section{Distinguishing features of TIL therapy in solid tumors and the current advances of clinical trials}

The following attributes of solid tumor may impose major challenges for developing effective adoptive cellular therapies. Different from hematological malignancies with lineage markers, the high heterogeneity of solid tumors makes it hard to find an ideal target for all tumor cells $[18,19]$. Targeting single tumor antigen usually leads to antigen loss or recurrence of more aggressive clones. Moreover, a large percentage of solid tumors is hard to be infiltrated even upon adoptive transfer of a large number of $\mathrm{T}$ cells [20,21]. In addition, it is difficult for $\mathrm{T}$ cells to fully exert their function in the tumor microenvironment (TME) due to multiple immune suppressive mechanisms, including but not limited to the upregulation of immune inhibitory molecules, cytokines and metabolites, downregulation of co-stimulatory

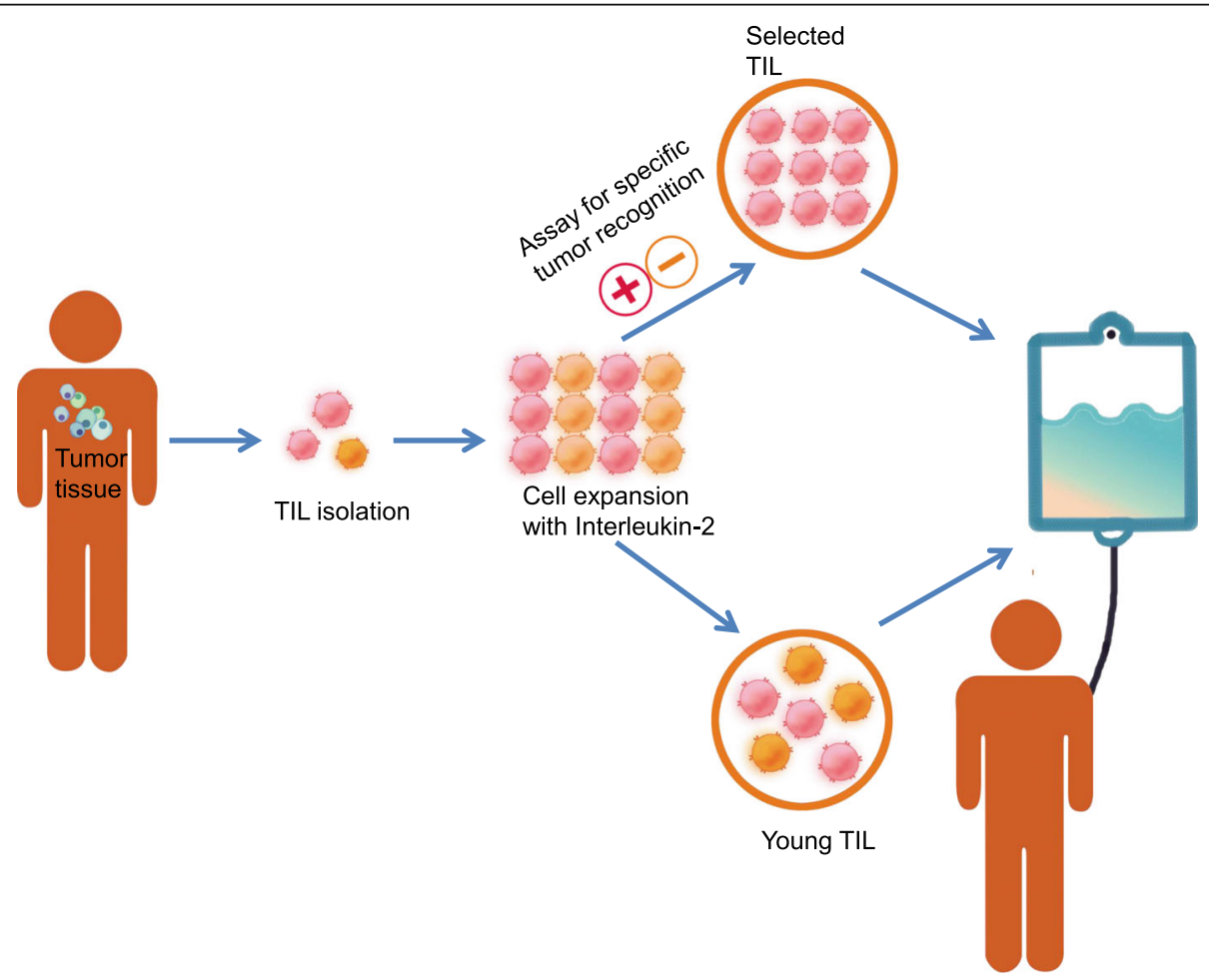

Fig. 1 Schematic representation of the production process for TIL therapy. After tumor excision from the patient, tumor is digested into small fragments or a single cell suspension and then expanded in culture with IL-2. In the "selected TIL" approach, expanded cells are selected by their recognition of autologous tumor cells; on the contrary, the "young TIL" approach leaves out this selection step. Then, the TIL culture is expanded to a clinically relevant level and infused back into the patient 
molecules, and the presence of immune regulatory subsets, such as Tregs, myeloid-derived suppressor cells (MDSCs), and tumor-associated macrophages (TAMs) $[22,23]$.

TIL may hold some distinguishing advantages for treating solid tumors. Firstly, TIL is composed of T cells with multiple $\mathrm{T}$ cell receptor (TCR) clones capable of recognizing an array of tumor antigens, and therefore may be superior in tackling the tumor heterogeneity compared to other adoptive cellular therapies, such as chimeric antigen receptor $\mathrm{T}(\mathrm{CAR}-\mathrm{T})$ and $\mathrm{TCR}-\mathrm{T}$ cell therapy. In line with this, TIL has demonstrated better clinical efficacy than CAR-T in solid tumors containing high mutation load, such as melanoma [24, 25]. Secondly, having been stimulated by tumor antigens in vivo, TIL tends to dominantly consist of effect memory $\mathrm{T}$ (Tem) cells, which express chemokine receptors on the surface, such as CCR5 and CXCR3 [26, 27]. Together with their tumor-specific TCRs, TIL can easily home to antigenically distinct tissues, including tumors, after transferred into patients [28-31]. Last but not least, offtarget toxicity has seldom been reported in TIL therapy probably due to the negative selection of TCRs of TIL during the early development of $\mathrm{T}$ cell immunity. On the contrary, the engineered tumor-targeting singlechain variable fragments ( $\mathrm{scFv}$ ) in CAR-T or affinityenhanced TCR in TCR-T product may lead to toxicity if they bear cross-reactivity with antigens on normal tissues [32, 33].

In recent years, there have been 79 trials of TIL therapy including 22 kinds of TIL products between 2011 and 2020 (Fig. 2). The trial numbers peaked in 2018 and 2019, along with the success of two phase II trials of TIL products LN144 [34, 35] and LN145 [36] by Iovance in 2018. Currently, 54\% (43/79) trials are open, 17\% (13/ 79) have been completed and the rest are either closed or terminated (Fig. 3). Geographic analysis shows that
$51 \%(40 / 79)$ of these trials are in the USA and 15\% (12/ 79) are in China (Fig. 3). TIL therapy has mainly been tested as the second treatment line (Fig. 4). Melanoma is still the top tumor type with most clinical trials, followed by non-small cell lung cancer (NSCLC), ovarian cancer, and head and neck cancer (Fig. 4). So far, TIL therapy has shown impressive clinical benefits in metastatic melanoma [37] and advanced cervical cancer [38], even in patients treated with checkpoint inhibitors [39]. Preliminary efficacy has also been demonstrated in NSCLC [40], colorectal cancer (CRC) [41], and breast cancer [42]. The administration of high-dose IL-2 used as standard of care to support the growth and activity of infused TIL [43], however, may restrain the clinical application of TIL therapy. High-dose IL-2 oftentimes induces systemic toxicity that requires intensive monitoring and care $[44,45]$, and could also promote regulatory $\mathrm{T}$ cells that suppress the anti-tumor response of TIL [46]. Although a more than 30\% ORR can be achieved in trials with low or intermediate dose of IL-2 $[47,48]$, most TIL trials still go with high-dose IL-2 infusion. Furthermore, unsustained persistence in vivo and immune suppression in the harsh TME are also obstacles to achieve the maximal outcome of TIL therapy [49].

\section{Development of next-generation TIL therapy}

To reduce toxicities associated with high-dose IL-2 as well as improve the in vivo survival and function of the traditional TIL therapy, next-generation TIL product is under active investigation. Next-generation TIL is genetically modified TIL to either overexpress a gene of interest by viral transduction or knock out (KO) the target gene with technologies like CRISPR or TALEN. However, the development of next-generation TIL may face some major challenges. Gene editing can be technically difficult to achieve in TIL probably due to the varied

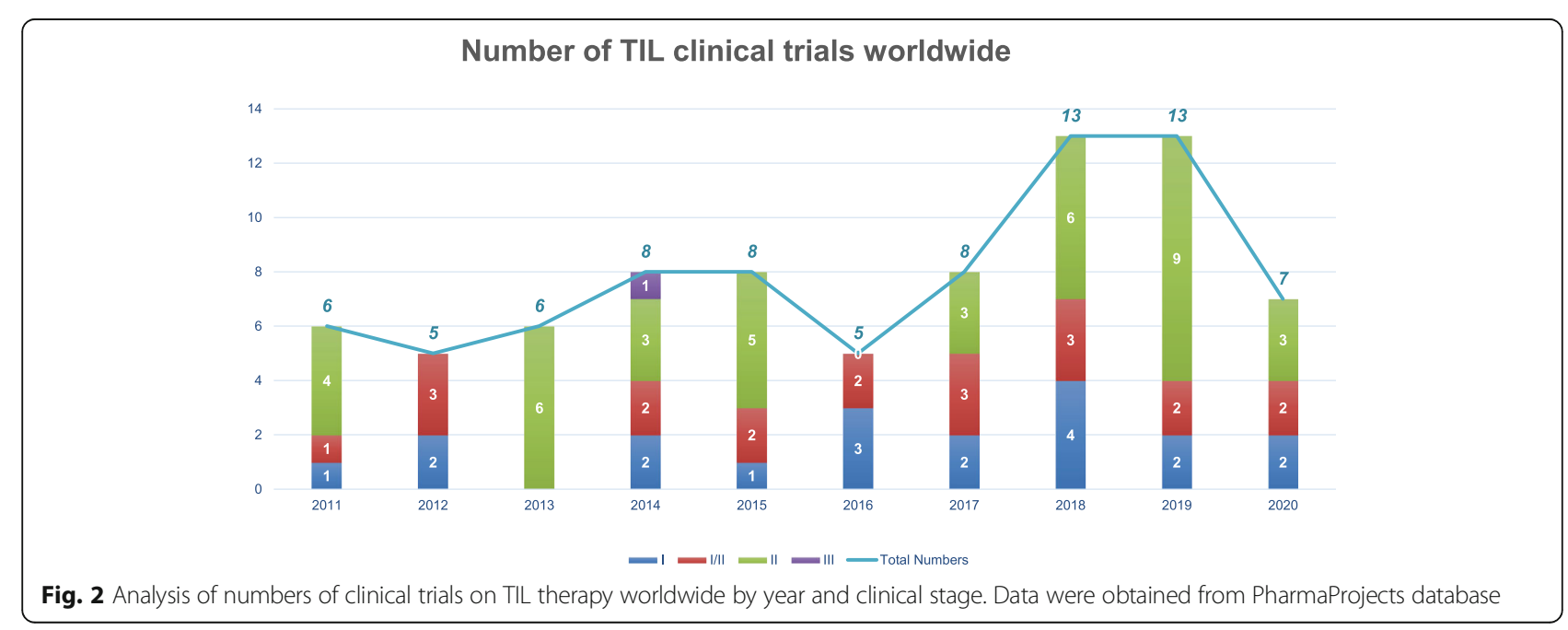




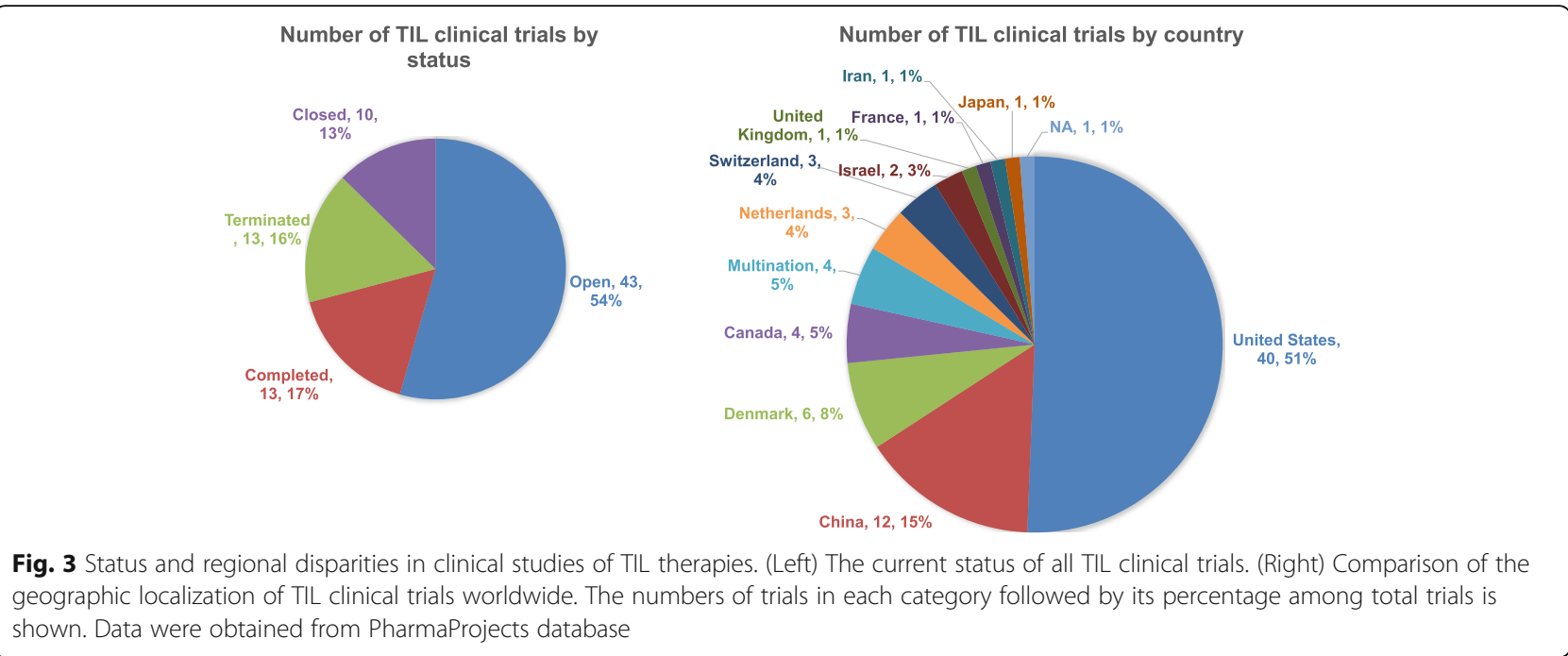

cellular composition and growth rates of TIL compared with PBMC. Forget et al. has described a method to transduce TIL by retrovirus, leading to transduction efficiency ranging from $\sim 31$ to $\sim 58 \%$ in TIL from metastatic melanoma and successful expansion to clinically relevant numbers, but high variability of transduction and expansion rate were observed among patients [50]. Moreover, it is critical but challenging to select the appropriate genes to be targeted in TIL.

So far, the attempts of next-generation TIL in the clinic mainly focused on engineering TIL to overexpress cytokines, such as IL-2 and IL-12. In a phase I/II trial, IL-2 insertion into TIL showed enhanced survival in vitro after IL-2 withdraw but little improvement of persistence in vivo and clinical efficacy [51]. Only $2 / 12$ (17\%) ORR was observed in patients who received IL-2 transduced TIL compared to $\sim 50 \%$ ORR with non- modified TIL along with high-dose IL-2. Another phase I trial using TIL transduced with IL-12 expressed under the control of a nuclear factor of activated $\mathrm{T}$ cells (NFAT)-inducible promoter showed favorable clinical efficacy in metastatic melanoma-63\% ORR was achieved in patients treated with $0.3-3 \mathrm{e}^{9}$ NFAT-IL- 12 engineered TILs, which is 10-100-fold less than the cell number used in the traditional TIL therapy [52]. However, unexpected high level of IL-12 and IFN- $\gamma$ in the serum together with significant toxicity was also observed. On the other hand, the feasibility and functionality of genetically $\mathrm{KO}$ of $\mathrm{T}$ cell negative regulators in TIL, such as PD-1 [53] and CISH [54], is also being actively tested at pre-clinical stage. How to rationally select or identify the target genes conveying the most benefits for TIL therapy still remains to be explored. In this regard, screening using CRISPR technologies $[55,56]$, including CRISPR

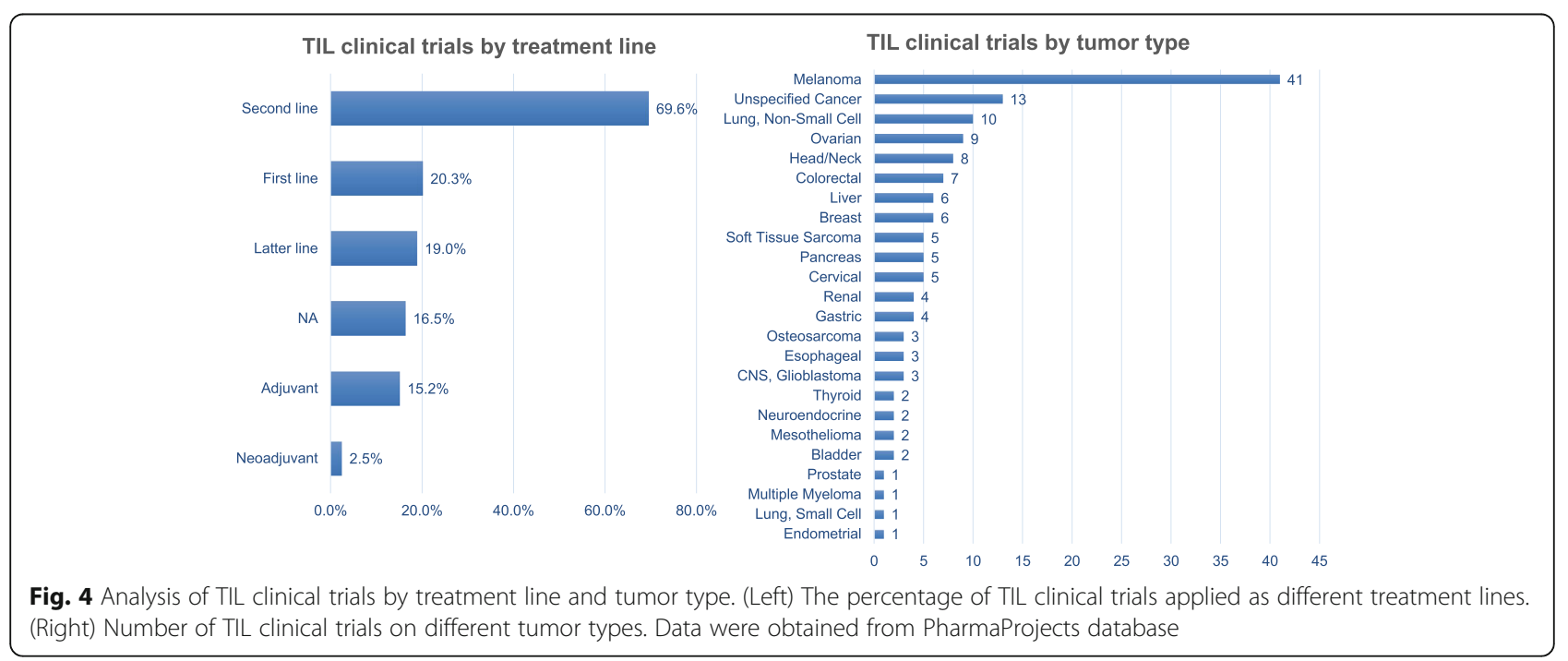


$\mathrm{KO}$, interference (CRISPRi) or activation (CRISPRa), may be promising strategies to identify novel targets for TIL. Moreover, comprehensive safety and function evaluation of genetically modified TIL is required before moving into the clinic. In addition to in vitro characterization, animal models remain to be established to better understand the persistence, function as well as toxicity of modified TIL in vivo.

\section{Conclusions}

Cancer immunotherapy represented by checkpoint inhibitors, especially anti-PD-1/PD-L1 antibodies, and adoptive cellular therapies, such as CAR-T and TCR-T, has revolutionized the field of cancer treatment and significantly prolonged the survival of patients with advanced cancers $[57,58]$. However, the response rate is still limited in most cancer types, especially solid tumors [59], which calls for the development of alternative therapeutic strategies. TIL holds some unique advantages in tackling solid tumors, but the laborious, expensive, and time-consuming tissue collection and production process makes TIL only be developed at some leading research institutions and companies in a few countries. There is still considerable room for further improvement and a broader application of this therapeutic approach, for instance, how to establish a standardized and stable production process of TIL from different patients, how to tailor the process based on the features of different tumor types, how to enrich tumorspecific TIL without largely increasing the process time, and how to select prognosis markers to identify patients that potentially benefit the most.

The development of gene-modified TIL holds promise to enhance the clinical outcome of TIL therapy across more indications as well as to enhance safety by decreasing the dependence on high-dose IL-2 infusion and lymphodepletion. Nevertheless, target selection and comprehensive functional evaluation could be critical steps for a successful next-generation product. On the other hand, the combination of TIL therapy with anti-PD1/PD-L1 antibodies that blockade the immune suppression mediated by the PD pathway at the tumor site showed preliminary favorable outcomes in some recent trials $[40,60]$. Other combinational approaches, such as TIL therapy combined with oncolytic viruses, are also under exploration. Similar to CAR-T therapies that show excellent responses in the second- or the third-line setting, there is considerable interest in moving TIL therapy to first-line treatment. The blossom of novel drug investigation at the neoadjuvant and adjuvant stage of treatment also brings opportunity to TIL. Although the development of TIL therapy is currently still in its infancy in China, the advent of CAR-T therapy has helped build a good macroenvironment for cell therapy and gene editing industry.
The collaboration and joint efforts from research institutions, biotech companies, hospitals as well as the government would drive this field ahead and facilitate the application of TIL therapy to a broader population of patients with solid tumors.

\section{Acknowledgements \\ None.}

\section{Authors' contributions}

$\mathrm{N}$ Li and Y Liu conceived the idea and structure for the review. S Wang and

J Sun conducted the literature search and produced the first draft. K Chen

plotted the figures. All other authors critically reviewed and edited

subsequent drafts. The authors read and approved the final manuscript.

\section{Funding}

This work was supported by Chinese Academy of Medical Sciences

Innovation Fund for Medical Sciences (Platform Improvement of Clinical Trial Capability 2020-12M-2-007), Chinese Academy of Medical Sciences (grants

2019XK320068), and Beijing Municipal Science and Technology Commission (International Pharmaceutical Clinical Research and Development Platform

2015) and non-profit central research Institute fund of Chinese academy of medical sciences (2019PT3200003).

Availability of data and materials

Not applicable (review).

\section{Declarations}

Ethics approval and consent to participate

Not applicable (review).

\section{Consent for publication}

All authors give consent for the publication of this manuscript

\section{Competing interests}

The authors declare that they have no competing interests.

\section{Author details}

${ }^{1}$ Clinical Cancer Center, National Cancer Center/National Clinical Research Center for Cancer/Cancer Hospital, Chinese Academy of Medical Sciences and Peking Union Medical College, Beijing, China. ${ }^{2}$ Grit Biotechnology Ltd., Shanghai, China. ${ }^{3} \mathrm{NHC}$ Key Laboratory of Pulmonary Immunological Diseases, Guizhou Provincial People's Hospital, Guiyang, China. ${ }^{4}$ Queen Mary School, Nanchang University, Nanchang 330006, China. ${ }^{5}$ Geneplus-Shenzhen, Shenzhen, China.

Received: 18 March 2021 Accepted: 13 May 2021

Published online: 11 June 2021

\section{References}

1. Rosenberg SA, Packard BS, Aebersold PM, Solomon D, Topalian SL, Toy ST, et al. Use of tumor-infiltrating lymphocytes and interleukin-2 in the immunotherapy of patients with metastatic melanoma. A preliminary report. N Engl J Med. 1988;319(25):1676-80.

2. Eberlein TJ, Rosenstein M, Rosenberg SA. Regression of a disseminated syngeneic solid tumor by systemic transfer of lymphoid cells expanded in interleukin 2. J Exp Med. 1982;156(2):385-97.

3. Rosenberg SA, Spiess P, Lafreniere R. A new approach to the adoptive immunotherapy of cancer with tumor-infiltrating lymphocytes. Science. 1986:233(4770):1318-21.

4. Huang J, Khong HT, Dudley ME, El-Gamil M, Li YF, Rosenberg SA, et al. Survival, persistence, and progressive differentiation of adoptively transferred tumor-reactive T cells associated with tumor regression. J Immunother. 2005;28(3):258-67.

5. Powell DJ Jr, Dudley ME, Robbins PF, Rosenberg SA. Transition of late-stage effector T cells to CD27+ CD28+ tumor-reactive effector memory T cells in humans after adoptive cell transfer therapy. Blood. 2005;105(1):241-50. 
6. Dudley ME, Wunderlich JR, Shelton TE, Even J, Rosenberg SA. Generation of tumor-infiltrating lymphocyte cultures for use in adoptive transfer therapy for melanoma patients. J Immunother. 2003;26(4):332-42.

7. Wu R, Forget MA, Chacon J, Bernatchez C, Haymaker C, Chen JQ, et al. Adoptive Tcell therapy using autologous tumor-infiltrating lymphocytes for metastatic melanoma: current status and future outlook. Cancer J. 2012;18(2):160-75.

8. Tran KQ, Zhou J, Durflinger KH, Langhan MM, Shelton TE, Wunderlich JR, et al. Minimally cultured tumor-infiltrating lymphocytes display optimal characteristics for adoptive cell therapy. J Immunother. 2008;31(8):742-51.

9. Donia M, Junker N, Ellebaek E, Andersen MH, Straten PT, Svane IM. Characterization and comparison of 'standard' and 'young' tumourinfiltrating lymphocytes for adoptive cell therapy at a Danish translational research institution. Scand J Immunol. 2012;75(2):157-67.

10. Dudley ME, Gross CA, Somerville RP, Hong Y, Schaub NP, Rosati SF, et al. Randomized selection design trial evaluating CD8+-enriched versus unselected tumor-infiltrating lymphocytes for adoptive cell therapy for patients with melanoma. J Clin Oncol. 2013;31(17):2152-9.

11. Hall M, Liu H, Malafa M, Centeno B, Hodul PJ, Pimiento J, et al. Expansion of tumor-infiltrating lymphocytes (TIL) from human pancreatic tumors. J Immunother Cancer. 2016;4:61.

12. Friese $C$, Harbst K, Borch TH, Westergaard MCW, Pedersen M, Kverneland A, et al. CTLA-4 blockade boosts the expansion of tumor-reactive CD8(+) tumor-infiltrating lymphocytes in ovarian cancer. Sci Rep. 2020;10(1):3914.

13. Frank L, Simpson AM, Lotze M, Ritthipichai K, Mosychuk C. The T-cell Growth Factor Cocktail IL-2/IL-15/IL-21 Enhances Expansion and Effector Function of Tumor-Infiltrating $T$ cells in a Novel Process Developed by lovance. Society for Immunotherapy of Cancer. 2017.

14. Le DT, Durham JN, Smith KN, Wang H, Bartlett BR, Aulakh LK, et al. Mismatch repair deficiency predicts response of solid tumors to PD-1 blockade. Science. 2017:357(6349):409-13.

15. Forde PM, Chaft JE, Smith KN, Anagnostou V, Cottrell TR, Hellmann MD, et al. Neoadjuvant PD-1 Blockade in Resectable Lung Cancer. N Engl J Med. 2018;378(21):1976-86.

16. Davidson TB, Lee A, Hsu M, Sedighim S, Orpilla J, Treger J, et al. Expression of PD-1 by T Cells in Malignant Glioma Patients Reflects Exhaustion and Activation. Clin Cancer Res. 2019;25(6):1913-22.

17. Jedema I, van de Meent M, Pots J, Kester MG, van der Beek MT, Falkenburg $J H$. Successful generation of primary virus-specific and anti-tumor T-cell responses from the naive donor T-cell repertoire is determined by the balance between antigen-specific precursor T cells and regulatory $\mathrm{T}$ cells. Haematologica. 2011;96(8):1204-12.

18. Hanahan D, Weinberg RA. Hallmarks of cancer. the next generation. Cell. 2011;144(5),646-74.

19. Vogelstein B, Papadopoulos N, Velculescu VE, Zhou S, Diaz LA Jr, Kinzler KW. Cancer genome landscapes. Science. 2013;339(6127):1546-58.

20. Galluzzi L, Chan TA, Kroemer G, Wolchok JD, Lopez-Soto A. The hallmarks of successful anticancer immunotherapy. Sci Transl Med. 2018;10:459.

21. Majzner RG, Mackall CL. Clinical lessons learned from the first leg of the CAR T cell journey. Nat Med. 2019;25(9):1341-55.

22. Sharma P, Hu-Lieskovan S, Wargo JA, Ribas A. Primary, Adaptive, and Acquired Resistance to Cancer Immunotherapy. Cell. 2017;168(4):707-23.

23. Anderson KG, Stromnes IM, Greenberg PD. Obstacles Posed by the Tumor Microenvironment to T cell Activity: A Case for Synergistic Therapies. Cancer Cell. 2017;31(3):311-25.

24. Schumacher TN, Schreiber RD. Neoantigens in cancer immunotherapy. Science. 2015;348(6230):69-74.

25. Titov A, Zmievskaya E, Ganeeva I, Valiullina A, Petukhov A, Rakhmatullina A, et al. Adoptive Immunotherapy beyond CAR T-Cells. Cancers (Basel). 2021;13:4.

26. Bedognetti D, Spivey TL, Zhao Y, Uccellini L, Tomei S, Dudley ME, et al. CXCR3/CCR5 pathways in metastatic melanoma patients treated with adoptive therapy and interleukin-2. Br J Cancer. 2013;109(9):2412-23.

27. Mikucki ME, Fisher DT, Matsuzaki J, Skitzki JJ, Gaulin NB, Muhitch JB, et al. Non-redundant requirement for CXCR3 signalling during tumoricidal T-cell trafficking across tumour vascular checkpoints. Nat Commun. 2015;6:7458.

28. van Kooyk Y, van de Wiel-van Kemenade P, Weder P, Kuijpers TW, Figdor CG. Enhancement of LFA-1-mediated cell adhesion by triggering through CD2 or CD3 on T lymphocytes. Nature. 1989;342(6251):811-3.

29. Burbach BJ, Medeiros RB, Mueller KL, Shimizu Y. T-cell receptor signaling to integrins. Immunol Rev. 2007;218:65-81.

30. Mirenda V, Jarmin SJ, David R, Dyson J, Scott D, Gu Y, et al. Physiologic and aberrant regulation of memory T-cell trafficking by the costimulatory molecule CD28. Blood. 2007;109(7):2968-77.
31. Sackstein R, Schatton T, Barthel SR. T-lymphocyte homing: an underappreciated yet critical hurdle for successful cancer immunotherapy. Lab Invest. 2017;97(6):669-97.

32. Cameron BJ, Gerry AB, Dukes J, Harper JV, Kannan V, Bianchi FC, et al. Identification of a Titin-derived HLA-A1-presented peptide as a crossreactive target for engineered MAGE A3-directed T cells. Sci Transl Med. 2013;5(197):197ra03.

33. Morgan RA, Chinnasamy N, Abate-Daga D, Gros A, Robbins PF, Zheng Z, et al. Cancer regression and neurological toxicity following anti-MAGE-A3 TCR gene therapy. J Immunother. 2013;36(2):133-51.

34. Sarnaik A, Khushalani N, Chesney J, Kluger H, Curti B, Lewis K, et al. P865 Safety \& efficacy of lifileucel (LN-144) tumor infiltrating lymphocyte therapy in metastatic melanoma patients after progression on multiple therapies independent review committee data update. J ImmunoTher Cancer. 2020; 8(Suppl 1):A12-A.

35. Sarnaik A, Khushalani NI, Chesney JA, Lewis KD, Medina TM, Kluger HM, et al. Long-term follow up of lifileucel (LN-144) cryopreserved autologous tumor infiltrating lymphocyte therapy in patients with advanced melanoma progressed on multiple prior therapies. J Clin Oncol. 2020;38(15_suppl): 10006.

36. Jazaeri AA, Zsiros E, Amaria RN, Artz AS, Edwards RP, Wenham RM, et al. Safety and efficacy of adoptive cell transfer using autologous tumor infiltrating lymphocytes (LN-145) for treatment of recurrent, metastatic, or persistent cervical carcinoma. J Clin Oncol. 2019;37(15_suppl):2538.

37. Rosenberg SA, Yang JC, Sherry RM, Kammula US, Hughes MS, Phan GQ, et al. Durable complete responses in heavily pretreated patients with metastatic melanoma using T-cell transfer immunotherapy. Clin Cancer Res. 2011;17(13):4550-7.

38. Stevanovic S, Draper LM, Langhan MM, Campbell TE, Kwong ML, Wunderlich JR, et al. Complete regression of metastatic cervical cancer after treatment with human papillomavirus-targeted tumor-infiltrating T cells. J Clin Oncol. 2015;33(14):1543-50.

39. Sarnaik A, Khushalani NI, Chesney JA, Kluger HM, Curti BD, Lewis KD, et al. Safety and efficacy of cryopreserved autologous tumor infiltrating lymphocyte therapy (LN-144, lifileucel) in advanced metastatic melanoma patients who progressed on multiple prior therapies including anti-PD-1. J Clin Oncol. 2019;37(15_suppl):2518-

40. Creelan B, Wang C, Teer J, Toloza E, Mullinax J, Yao J, et al. Abstract CT056: Durable complete responses to adoptive cell transfer using tumor infiltrating lymphocytes (TIL) in non-small cell lung cancer (NSCLC): A phase I trial. Cancer Res. 2020;80(16 Supplement):CT056-CT.

41. Tran E, Robbins PF, Lu YC, Prickett TD, Gartner JJ, Jia L, et al. T-Cell Transfer Therapy Targeting Mutant KRAS in Cancer. N Engl J Med. 2016;375(23): 2255-62.

42. Zacharakis N, Chinnasamy H, Black M, Xu H, Lu YC, Zheng Z, et al. Immune recognition of somatic mutations leading to complete durable regression in metastatic breast cancer. Nat Med. 2018:24(6):724-30.

43. Atkins MB, Lotze MT, Dutcher JP, Fisher RI, Weiss G, Margolin K, et al. Highdose recombinant interleukin 2 therapy for patients with metastatic melanoma: analysis of 270 patients treated between 1985 and 1993. J Clin Oncol. 1999;17(7):2105-16.

44. Schwartz RN, Stover L, Dutcher JP. Managing toxicities of high-dose interleukin-2. Oncology (Williston Park). 2002;16(11 Suppl 13):11-20.

45. Lotze MT, Matory YL, Rayner AA, Ettinghausen SE, Vetto JT, Seipp CA, et al. Clinical effects and toxicity of interleukin-2 in patients with cancer. Cancer. 1986;58(12):2764-72

46. Yao X, Ahmadzadeh M, Lu YC, Liewehr DJ, Dudley ME, Liu F, et al. Levels of peripheral CD4(+)FoxP3(+) regulatory $T$ cells are negatively associated with clinical response to adoptive immunotherapy of human cancer. Blood. 2012;119(24):5688-96.

47. Ellebaek E, Iversen TZ, Junker N, Donia M, Engell-Noerregaard L, Met O, et al. Adoptive cell therapy with autologous tumor infiltrating lymphocytes and lowdose Interleukin-2 in metastatic melanoma patients. J Transl Med. 2012;10:169.

48. Andersen R, Donia M, Borch TH, Steensgaard EE, Iversen TZ, Kongsted P, et al. Adoptive cell therapy with tumor infiltrating lymphocytes and intermediate dose IL-2 for metastatic melanoma. J ImmunoTher Cancer. 2014;2:S3

49. Robbins PF, Dudley ME, Wunderlich J, El-Gamil M, Li YF, Zhou J, et al. Cutting edge: persistence of transferred lymphocyte clonotypes correlates with cancer regression in patients receiving cell transfer therapy. J Immunol. 2004;173(12):7125-30 
50. Forget MA, Tavera RJ, Haymaker C, Ramachandran R, Malu S, Zhang M, et al. A Novel Method to Generate and Expand Clinical-Grade, Genetically Modified. Tumor-Infiltrating Lymphocytes. Front Immunol. 2017;8:908.

51. Heemskerk B, Liu K, Dudley ME, Johnson LA, Kaiser A, Downey S, et al. Adoptive cell therapy for patients with melanoma, using tumor-infiltrating lymphocytes genetically engineered to secrete interleukin-2. Hum Gene Ther. 2008; 19(5):496-510.

52. Zhang L, Morgan RA, Beane JD, Zheng Z, Dudley ME, Kassim SH, et al. Tumor-infiltrating lymphocytes genetically engineered with an inducible gene encoding interleukin-12 for the immunotherapy of metastatic melanoma. Clin Cancer Res. 2015;21(10):2278-88.

53. Ritthipichai K, Machin M, Lakshmipathi S, Juillerat A, Poirot L, Fardis M, et al. Genetic Modification of lovance's TIL through TALEN-mediated knockout of PD-1 as a strategy to empower TIL therapy for cancer. Eur Soc Med Oncol Congress. 2020.

54. Palmer DC, Webber BR, Patel Y, Johnson MJ, Kariya CM, Lahr WS, et al. Internal checkpoint regulates T cell neoantigen reactivity and susceptibility to PD1 blockade. bioRxiv. 2020:2020.09.24.306571.

55. Shifrut E, Carnevale J, Tobin V, Roth TL, Woo JM, Bui CT, et al. Genome-wide CRISPR Screens in Primary Human T Cells Reveal Key Regulators of Immune Function. Cell. 2018;175(7):1958-71 e15.

56. Dong MB, Wang G, Chow RD, Ye L, Zhu L, Dai X, et al. Systematic Immunotherapy Target Discovery Using Genome-Scale In Vivo CRISPR Screens in CD8 T Cells. Cell. 2019;178(5):1189-204 e23.

57. Couzin-Frankel J. Breakthrough of the year 2013. Cancer Immunother Sci. 2013;342(6165):1432-3.

58. June $\mathrm{CH}, \mathrm{O}$ 'Connor RS, Kawalekar OU, Ghassemi S, Milone MC. CAR T cell immunotherapy for human cancer. Science. 2018;359(6382):1361-5.

59. Ribas A, Wolchok JD. Cancer immunotherapy using checkpoint blockade. Science. 2018;359(6382):1350-5.

60. Wang C, Li M, Wei R, Wu J. Adoptive transfer of TILs plus anti-PD1 therapy: An alternative combination therapy for treating metastatic osteosarcoma. $J$ Bone Oncol. 2020;25:100332.

\section{Publisher's Note}

Springer Nature remains neutral with regard to jurisdictional claims in published maps and institutional affiliations.

Ready to submit your research? Choose BMC and benefit from:

- fast, convenient online submission

- thorough peer review by experienced researchers in your field

- rapid publication on acceptance

- support for research data, including large and complex data types

- gold Open Access which fosters wider collaboration and increased citations

- maximum visibility for your research: over $100 \mathrm{M}$ website views per year

At $\mathrm{BMC}$, research is always in progress.

Learn more biomedcentral.com/submissions 